\title{
THE INFLUENCE OF SEVERE ILLNESS ON RICKETS*
}

\author{
BY \\ EDWARDS A. PARK \\ Professor Emeritus of Pediatrics, Johns Hopkins University School of Medicine, Baltimore, Maryland
}

(RECEIVED FOR PUBLICATION APRIL 1, 1954)

In my first lecture I discussed the effects of illness on the cells and cartilage of normal bone. Today I show their effects in rickets. First, what is the characteristic pattern in the bone in rickets uncomplicated by any other condition and is the response to severe illness different from that of normal bone? Next I shall take up the effects of illness on the calcium-phosphorus equilibrium in the blood, that is on rickets itself, since the changes in cartilage and bone depend directly on the changes in the tissue fluid and only indirectly on vitamin $\mathrm{D}$ deficiency. The effects on the cells in rickets pertain to growth, but those on the calcifying mechanism are at the heart of rickets itself. Is it by its effects there that illness precipitates rickets and once established, makes it worse, or in certain circumstances may it prevent its development altogether, or produce a partial or complete cure? There is evidence in favour of each view.

\section{The Influence of Rickets on Growth}

Cellular Pattern in the Shaft in Uncomplicated Rickets. Before discussing the effects of severe illness on the osteoblastic cells in rickets, we must know exactly what the cellular pattern is in its Simon purity. Fortunately, in Follis's and my series of children cases in which death had occurred suddenly or after short illnesses furnished the information. In brief the trabeculae were covered with thick cloaks of osteoblasts, many of which were enormous (Fig. 5, A and B). That they were in a state of increased activity, one could tell in occasional instances because the osteocytes in the osteoid were further separated by matrix substance than in the adjacent calcified bone laid down in the prerachitic period; in other words, the production of rachitic matrix substance had been excessive (Fig. 5c). Evidently in rickets in its purity the cellular proliferation and activity in the bone tend to be intensified rather than inhibited. In respect

\footnotetext{
* The second of two inaugural Leonard Parsons Lectures delivered
} in Birmingham in 1953. of the large numbers and large size of the osteoblasts the picture was comparable to that in the prematurely born infant.

An Explanation for the Great Activity of the Bone Cells. Schmorl (1909) furnished a teleological explanation for the increased thickness which the long bones sometimes develop in rickets and expressed the opinion that an excess of material was required to offset its poor quality. This may well be true, on account of the increased disposition of the bone to be compressed because of its lack of calcium salts, and as a result the cellular regulators, which are to be conceived of as continuously adjusting the bone mass to fit the requirements of stress and strain, must be kept in constant stimulation. In our view the regulating cellular mechanism for the cortex must reside in the periosteum and for the interior of the bone in the endosteal sheaths of the trabeculae and perhaps the osteocytes themselves.

Effect of Severe Illness on the Osteoblastic Cells. Skipping details, the effects are exactly the same in the rachitic as in the non-rachitic subject. The thick covering layers of huge cells vanish and in their places are scattered spindle cells, small osteoclasts, and the sparse flattened cells of the endosteal membrane. For a long time we were much puzzled by the contradiction of thick osteoid borders and a covering of cells too scant to have produced them (Fig. 5D). We finally realized that severe illness treated the rachitic bone exactly like the nonrachitic; the osteoid borders had been formed before the illness had produced its blighting effect and the scanty coverings of the trabeculae represented the atrophied remains of luxurious growths (Fig. 5E).

But it must not be concluded that the bone cells in severe rickets always responded in this way. Just as in some non-rachitic children the cells of the shaft seemed able to weather the storm, so in some cases of rickets osteoblastic proliferation and activity appeared unimpeded. 

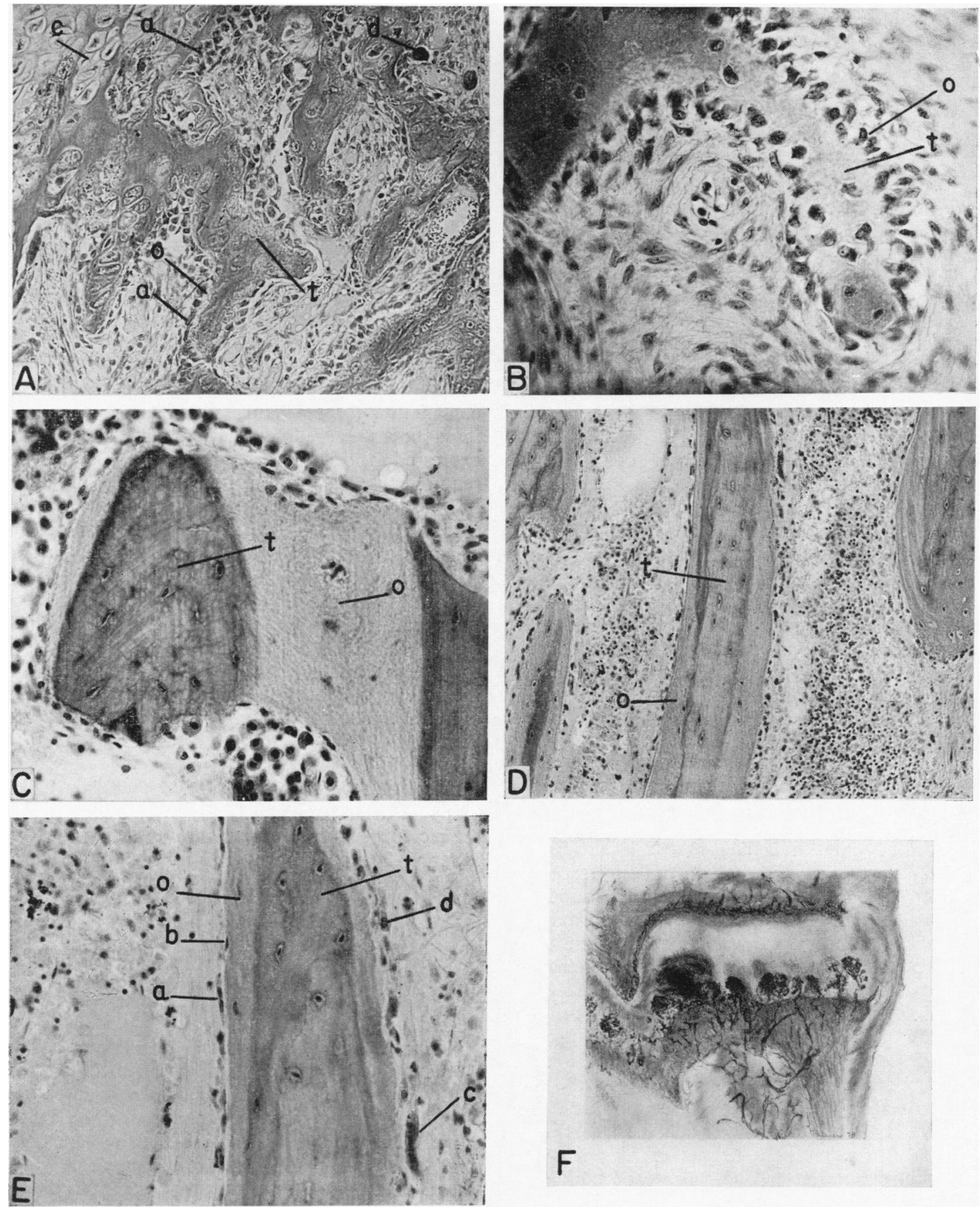

Fig. 5. 
Dissociation of Cartilage Cell and Osteoblasts in Rickets. In the preceding lecture I pointed out the differences in behaviour of the cartilage cell and the osteoblast in normal bone under the same environment, which Follis and I have termed 'dissociation'. In rachitic children suffering from severe illness, we encountered this same dissociation, which appeared as in extreme manifestations of rickets in the cartilage and none (no osteoid) in the shaft. In 20 cases of moderate or severe rickets all the changes were cartilaginous; there was no osteoid. The absence of osteoid meant one of three possibilities: either it had never formed, or had disintegrated, or had become calcified and had disappeared by losing its identity. But this last possibility could be excluded because corresponding healing counterparts were absent in the cartilage. Of the alternatives left, the probable one was that the osteoid had not formed. That this was so was indicated in numerous cases in which well developed osteoid borders sheathed the trabeculae lower down in the section, the older ones, while there were none on the trabeculae near the cartilage, the most recently formed. This showed that the osteoblasts had ceased their building function which they had been

FIG. 5A.-28; $>$ 90. Rib of 5-months-old child; sudden death, unexplained; rickets severe. The trabeculae $(t)$ are covered with (a) osteoblasts, upper marked group cut tangentially; (o) osteoid; (c) rachitic cartilage; (d) osteoclasts.

FIG. 5B.-51; $\times$ 194. Rib of 8-months-old child, dying of heart failure in severe rickets. The proliferation of (o) osteoblasts is extremely marked and they are very large, comparable in that respect and also in number to the premature infant; $(t)$ trabecula composed mostly of cartilage matrix.

FIG. 5c.-1118; $\times$ 194. Rib of 10-months-old child, dying of extensive tuberculosis; rickets ,chronic severe. The paucity of the cells in the (o) osteoid is well shown as compared by those in ( $t$ ) calcified bone, the latter formed before the onset of the rickets. Also, the osteoid has only scattered covering of (b) osteoblasts in advanced regression.

FIG. 5D. $-187 ; \times 90$. Rib of 12 -months-old child dying of pneumococcal meningitis of four days' duration; rickets, chronic severe. (t) Calcified bone; (o) osteoid. Lining cells of osteoid in state of advanced regression, as shown in higher magnification, Fig. $5 \mathrm{E}$.

FIG. 5E.-187; higher magnification, $\times 194$, of preceding. (t) Calcified trabecula; (o) osteoid; (a) lining osteoblasts which appear to have fused; (b) single osteoblasts which appear to be destroying osteoid; (c) osteoclasts; (d) osteoclast and osteoblasts destroying osteoid. The breadth of the osteoid border means that, before the regressive changes started, they must have been covered with thick mantles of actively secreting osteoblasts. It is difficult to account for their disappearance.

Fig. 5F.-Drawing from the lower ulna in a case of severe rickets in which the blood vessels were injected with india ink. The injected blood vessels appear like bushes sticking out of the end of the shaft into the rachitic cartilage. The points explained in the text, namely, that the invasion occurs only here and there and that the blood vessels and osteoblasts may have to travel underneath the surface of the cartilage in order to find penetrable spots, are well illustrated. able to exercise before. In the earlier part of our work we speculated that, since osteoid lacked impregnation with calcium salts, it might also lack stability and be subject to disintegration or transformation into connective tissue and disappear totally in that way. But further study convinced us that osteoid was destroyed exactly like calcified bone through dissolution by its surface cells and that, when this occurred, it was always focal so that patches of it were left, indicating that it had been present previously in larger amount. We gained the impression from our examinations of many examples of severe chronic rickets that osteoid must be as durable as calcified bone, for the broad osteoid borders were excellently preserved, though they must have been there for a long time. Progressing rickets in the cartilage and none in the shaft must be explained by dissociation, the cartilage cell able to multiply and the osteoblasts unable to secrete bone matrix.

Difficulty of Assessing Effects of Severe Illness on Cartilage. The changes caused by illness in the osteoblasts were as easy to recognize in the rachitic as in the non-rachitic subject, for in both the cells were in sharp relief along the trabecular edges. But the problem of distinguishing the effects on the solid mass of the rachitic cartilage, already thrown into the utmost confusion by the rickets itself, was too difficult for solution. In the non-rachitic bone the absence of the zone of empty or semi-empty capsules along the shaft border indicated that the maturation cycle of the cartilage cell had stopped, and reduction in width (actually length) of the epiphyseal plate served almost as a measure of the degree of growth inhibition, even to cessation itself. But these criteria were abolished by the rickets. Rickets interrupts the senescent cycle of the cartilage cell, as will be explained presently, so that criterion was excluded and the characteristic piling up of the cartilage in front of the shaft, which keeps increasing the longer the rickets lasts, makes any inferences from measurement impossible. In rickets artificially induced in the rat longitudinal growth diminishes progressively until it virtually stops and in the spontaneously developing rickets of the human being with its naturally occurring phosphorus deficiency, growth in length must become ultimately reduced, though important additional factors in the dwarfing process are the constant vitiation of gained length by crushing of the cartilage as fast as produced and also bending of the legs. But though common sense told us that rickets per se could not confer any immunity, i.e. illness must have the same inhibiting effect on rachitic as on normal cartilage, we were 
totally unable to prove it. In the general confusion we could not establish that the proliferation rate was reduced or discover any structural counterpart to the growth retardation lattice. So, too, though we knew that the inactivation of the osteoblasts must have meant a diminished ability on the part of the shaft to invade the cartilage mass and reconstruct it into rachitic (osteoid) trabeculae, we could not find sure evidence that the process was interfered with. In severe chronic rickets the stasis and degenerative changes in the cartilage bordering on the shaft reach proportions which could scarcely be exceeded so that any additional interference would be masked by the general confusion. Our efforts, therefore, to establish growth disturbance in the cartilage when illness was superimposed on that inherent in the rickets itself failed completely.

Special Susceptibility of the Cartilage Cell. Rickets is characterized by deficiencies of phosphorus, calcium, or both in the tissue field, and the lesions in cartilage and bone depend directly on them and only indirectly on the vitamin $\mathrm{D}$ deficiency. A proof of this is the cure of the rickets by treatment with citrate, leaving the $D$ deficiency unrelieved (Harrison and Harrison, 1941). In the defective medium of the tissue fluid the osteoblasts can flourish, proliferating profusely and producing bone matrix even in excess, as previously emphasized. But the cartilage cell in contrast is completely stymied, being rendered unable to complete the normal maturation cycle essential for the invasion of the capillaries and osteoblasts and reconstruction of the matrix frame into shaft. The defect, then, so far as the osteoblasts are concerned, is not in themselves but lies only in the failure of their product, the osteoid, to calcify, a failure obviously traceable to the subnormal calcium-phosphorus concentrations in the tissue fluid. But the defect, so far as the cartilage is concerned, is a biological block in the middle of its maturation performance.

The Development of the Endochondral Lesion. The inability of the cartilage cell to reach the endpoint in its cycle makes impossible its invasion by the capillaries and osteoblasts, and this is the primary and essential cause of the piling up of cartilage masses at the end of the shaft. The secondary cause, as now explained, is mechanical. In normal growth the cartilage cell columns can be imagined as standing on end, parallel to each other, and capping the shaft. Each column is completely embedded in homogeneous matrix substance. For an easier understanding, the cartilage cell columns may be compared to the honey and the surrounding matrix to the comb. The capillaries, surrounded by the osteoblasts, are attracted by the cartilage cells (the honey) and attack them in perfect order, abreast, in parallel vertical lines corresponding to the cartilage cell columns, a capillary for each column. They advance gradually up the columns by breaking into one cartilage cell capsule after another. Coincidentally the osteoblasts begin the manufacture of the future trabeculae by layering over with bone the paper-thin matrix walls of the holes caused by the destruction of the cartilage cells (the walls of the cells). Calcification occurs, not in the cartilage cells, but in the matrix walls, chiefly the vertical ones between the columns, and it is most important to realize that it always takes place in advance of the invading capillaries and osteoblasts. Thus in their progress into the cartilage these lie in a system of tiny tunnels, formed by the boring out, so to speak, of the cartilage cell columns, the walls of which have been given a metallic rigidity by the calcium salt deposition. It is the rigidity of the tunnel walls imparted by this inorganic reinforcement which ensures the orderly invasion. Here then is the point: when calcification of the cartilage stops, the tiny tunnels, incompletely reinforced by calcium salt deposition, become crushed and collapse from stress and strain causing 'roadblocks' over wide areas. The areas where these blocks occur are in the lines of stress, i.e. at those points where the trabecular pillars (the main trabecular complexes) on which the cartilage plate rests, abut. As the result then of the combined failure of the cartilage cell to complete its biological cycle and the development of these blocks, the capillaries and attendant osteoblasts are forced to find entrance into the cartilage where they can. They do this ultimately between the compression areas where the resistance is less, but may be obliged to travel some distance along the under surfaces of the cartilage in their search for penetrable spots. Through these they ultimately pass, finally working their way deep within in spite of the unready state of the cartilage cells, destroying the enveloping cells and converting their matrix into rachitic bone, i.e. osteoid trabeculae. In the course of this they grow into huge, bush-like structures (Fig. 5F). In this general way the endochondral lesion of rickets comes into being. As soon as the calcium and phosphorus are restored to the tissue fluids, the normal cartilage cell cycle reestablishes itself, calcium salts precipitate and endochondral ossification becomes normal again. Coincidentally, the osteoid in the shaft also calcifies.

The Effects of Severe Illness on Calcification. I have given this detailed explanation of the genesis 


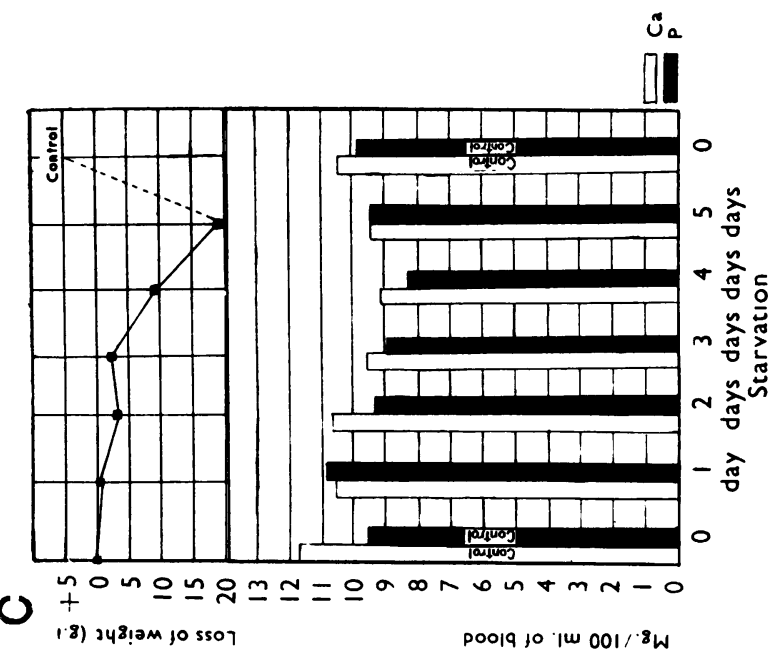

望

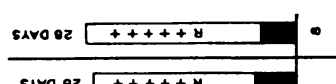

i.

savo $\angle++y$

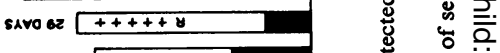

savo $1 2 \longdiv { 5 + + + y }$

savo $n+++y$

$\operatorname{savo} \angle+8$

savo oz

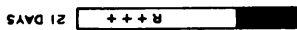

sivo $1+++y$

sive $<+y$

$\operatorname { s i v c o s } \longdiv { + t + + 4 }$

sivo $1 5 \longdiv { T + + 8 }$

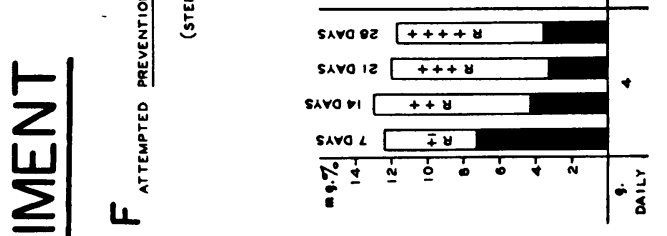

vo

堊

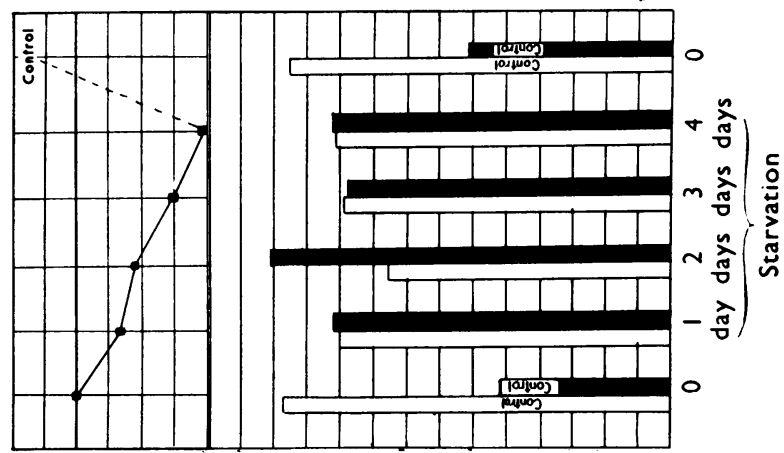

$\boldsymbol{m}$

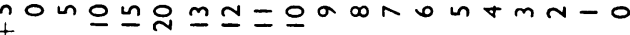

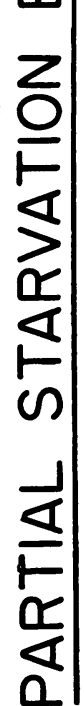

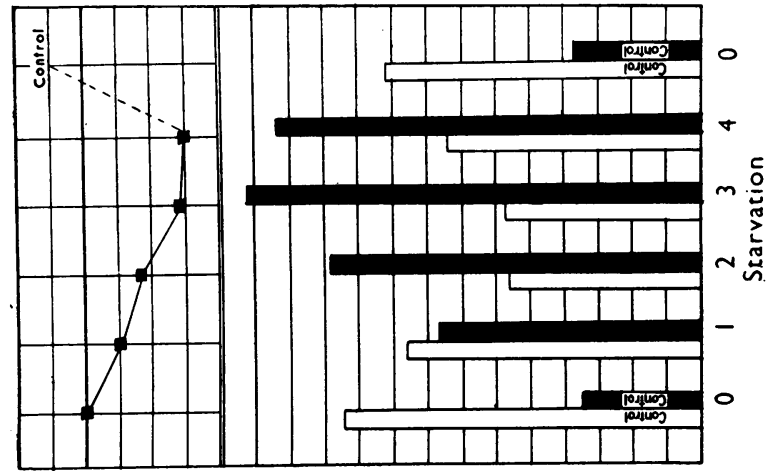

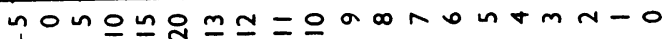
$\varangle$

(8) $34810 \mathrm{M} 10 \mathrm{s507}$

poola jo $10001 / .8 \mathrm{~W}$

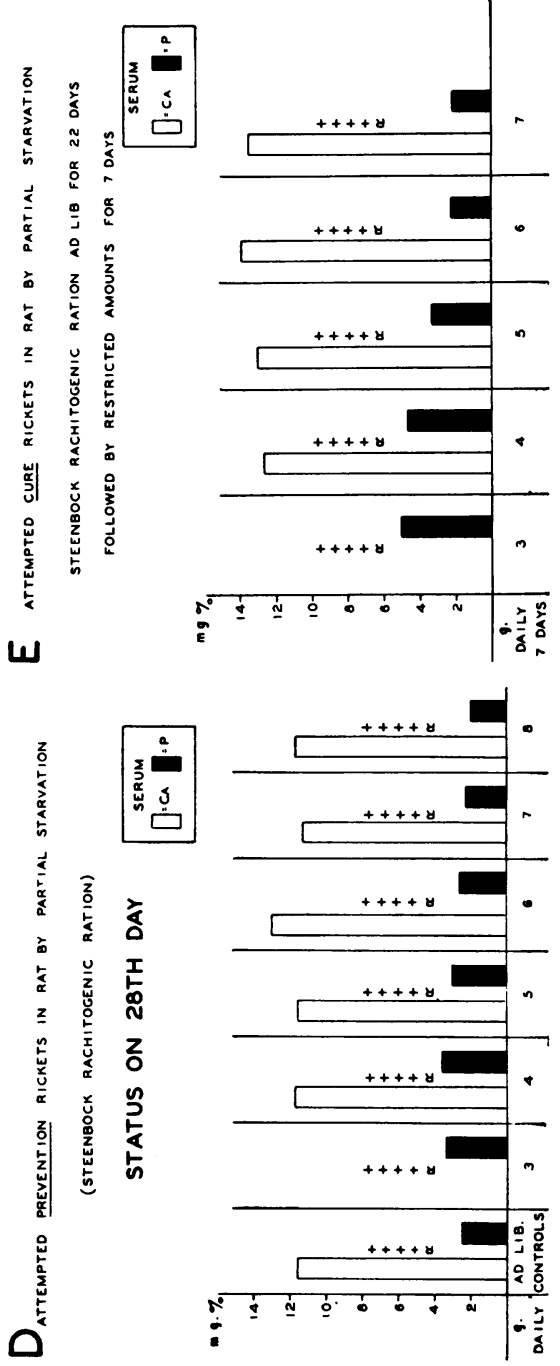

.

$\because=$

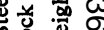

४ं के

ن

है ธิ

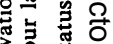

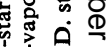

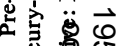

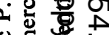

N

$\sum^{2}$

.0

要

2ิ

$\overrightarrow{\vec{g}}$

ชீ $\frac{0}{3}$

굴

.

ธ

등 응

वे

홍

을 을

잉

응

范

至

요

N

오

w

웅

듬

要?

音 뭉

웅 
of the endochondral lesion in rickets to show how directly determined it is by the defect in the calciumphosphorus equilibrium in the tissue fluids. I, therefore, now turn to the effects of severe illness on the calcifying mechanism in rickets, falling back first on experiments with the rat and afterwards on Follis's and my studies of rachitic children. As a preliminary, however, I must tell how extraneous illness could be conceived as affecting rickets.

How Illness could Promote or Oppose the Development of Rickets. Viewed from the 'pro' side, illness could precipitate or intensify rickets by diminishing the absorption of calcium and phosphorus from the gut and also the absorption of vitamin D. Associated acidosis could directly cause the loss of body calcium through its diversion into the kidney as a neutralizing base and at the same time could lower the renal threshold for phosphorus (Harrison and Harrison, 1952). It is easy to imagine that illness might interfere with the enzymatic reactions which end in the deposition of calcium salts in cartilage and bone and also with those specifically concerned with vitamin $\mathrm{D}$ action. I have demonstrated the visual effects of illness on the cells of cartilage and bone. The invisible chemical activities of the cells concerned with calcification may be interfered with all along the line.

From the 'anti' side I can think of only three ways in which illness could exert a healing influence, first through inanition, second through toxic effect, third by limitation of growth.

The experiments which I take up now all have to do with the action of inanition. Inanition is so often imposed by the severe infections that it may be considered almost a component part of their action. Moreover, in the nutritional group of Follis's and my series it appeared the central factor. Inanition could affect the body processes, so far as rickets is concerned, in two distinct ways; it could cause the liberation of phosphorus by forcing the body to feed on its own protein, and it could restrict growth. I was particularly impelled to study the effect of partial inanition on rickets, first because of the knowledge that total starvation did have a healing effect in rickets and, second, its investigation was simple. The information desired was, first, by what mechanism did inanition act and, second, could rickets be prevented and cured by partial inanition.

\section{Experimental Studies in Rats}

Effects of Complete Starvation on Rickets in the Rat. Years ago McCollum, Simmonds, Shipley and I (1922) demonstrated that starvation exerted a curative effect in the rachitic rat. The proof was the occurrence of a fresh calcium deposit in the cartilage topping the rachitic intermediate zone, exactly as in the vitamin D line test (Fig. 6A).

The Modus Operandi of Starvation. Dr. Elizabeth Harrison, working with me years ago at Yale University, made a study, never published, of the effects of complete starvation on the blood. This study showed why the deposition occurs. Rats just weaned, about 24 days old, were kept for 24 days on the Steenbock-Black ration and developed extreme rickets. At the end of the 24-day period a water diet was substituted. The inorganic phosphorus level of the serum rose from $3.5 \mathrm{mg}$. (control level) to $7 \cdot 8$ at the end of 24 hours, 10.9 at 48 , to the maxima of $13 \cdot 2 \mathrm{mg}$. at the end of 72 and $12 \cdot 3$ at the end of 96 hours. The calcium level dropped from $10.3 \mathrm{mg}$. \% (control level) to 8.7 at 24 hours and lay at approximately $5.6 \mathrm{mg}$. \% at 48 and 72 hours, rising to $7 \cdot 4$ at the end of 96 (Fig. 6A). Miss Harrison sought also-and this is not irrelevant, as will be evident later-to determine if radiation with ultra-violet light during the rachitic regime would prevent the marked shift in serum calcium and phosphorus. She found that it did make the rats resistant to starvation, since only a very slight shift occurred, nothing comparable to the degree in the untreated animals (Fig. 6B). She concluded that radiation with ultra-violet light either caused a better stocking of the skeleton with calcium or phosphorus-it prevented the rickets-or else preserved or actually increased the regulating power of the parathyroids. She also found that control rats fed stock diets showed, when starved, an almost complete stability of the calcium and phosphorus concentrations in the serum, a result favouring the first possibility (Fig. 6C).

Miss Harrison's experiments show the sharp rise in phosphorus and the fall in calcium which follow complete starvation. Evidently the rise in the phosphorus was enough to compensate for the lowering of the calcium. It produced an extremely abnormal equilibrium, resembling that seen in parathyroid tetany or more closely uraemia, which evidently, however, was capable of inducing precipitation. Miss Harrison's experiments also demonstrate beautifully the complete breakdown in rickets of the mechanism which regulates the calcium-phosphorus equilibrium in the body fluids. The radiated rats, synthesizing their own vitamin $D$, and those fed the stock diet were able to adapt so as to maintain during starvation normal calciumphosphorus levels in the blood, whereas the rachitic rat was helpless. How does starvation work to 
cause this sudden shift from the normal calcium and phosphorus pattern?

In complete starvation the glycogen of the tissues is rapidly used up, then the fat and protein are drawn upon. The protein yields phosphorus and it is the rise in phosphorus which is the factor responsible for the deposition of calcium salts. What actually happened in the rats of Miss Harrison's experiments is that the feed of the animal was abruptly changed from the rickets diet to its own tissues. This involved a transfer from a diet high in calcium and carbohydrate and extremely low in phosphorus and in fat to one high in fat and proteins, high in phosphorus and exceedingly low in calcium and lacking carbohydrate altogether. The rachitic rat, having lost all power to maintain the normal calcium-phosphorus in his body fluids became a prey to his diet and promptly reflected in his blood whatever the calcium-phosphorus pattern in the food happened to be. One could have obtained a shift in the calcium-phosphorus pattern identical with that induced by starvation by suddenly substituting for the Steenbock-Black rickets ration one high in protein and low in calcium and carbohydrate.

As a means of curing rickets total starvation obviously has only academic interest. By scaling downwards the amounts of food given, i.e. by partial starvation, we were hopeful of stopping rickets by stopping growth or by retarding it, and at the same time forcing the animal to metabolize his own tissues sufficiently so that the increased power of the blood to calcify would meet the requirement of the reduced new cartilage and bone formed. First I describe the partial starvation experiments planned to prevent rickets and afterwards the experiments planned to cure it by that means.

Attempts to Prevent Rickets by Partial Starvation. I now turn to unpublished experiments done years ago by Miss Deborah Jackson and myself to settle the point. Groups of rats, freshly weaned, were placed on varying quantities of the Steenbock-Black ration, namely on $3,4,5,6,7$ and $8 \mathrm{~g}$., respectively, per day. The plan was to kill them at the end of 28 days and then to measure the calcium and phosphorus in the pooled serum and examine the bones histologically. The group limited to the $2 \mathrm{~g}$. amounts died within a few days and passed out of the experiment. Those on the $3 \mathrm{~g}$. mostly died but six lived for the planned 28 days and all showed total rickets histologically. The groups on the 4,5 , 6,7 and $8 \mathrm{~g}$. amounts, when killed at the end of four weeks, also all showed severe rickets. The sole difference between the groups lay in the quantities of rachitic tissue produced. The rachitic intermediate zone (metaphysis) in the animals receiving the larger amounts of ration was much better developed, i.e. longer, than in those receiving the smaller amounts, indicating better growth, but absence of calcification was alike in all. The serum calcium levels in all groups were maintained approximately at the normal, $10 \mathrm{mg}$. \% (Fig. 6D). The serum inorganic phosphorus levels, on the other hand, were much lowered in all and, it is important to note, again showed an inverse relationship to the food allowances; in the animals on the two smallest feeds, namely 3 and $4 \mathrm{~g}$. per day, the inorganic phosphorus level was highest and it became proportionately less as the quantity of food increased. This result once more indicates that the body protein was catabolized inversely to the amounts of the feeds. As for the weights, the rats on the $3 \mathrm{~g}$. allowance lost slightly, those on the $4 \mathrm{~g}$., after initial loss, gained slightly and those on the larger intakes gained proportionately. The examination of the bones showed that all, including the $3 \mathrm{~g}$. allowance group, grew in length, inversely, however, to the size of the intakes.

We thought it would be interesting to trace the evolution of the rickets week by week. Accordingly additional groups of animals on the 4, 5 and $6 \mathrm{~g}$. daily allowances were killed seriatim after seven, 14,21 and 28 days and one group on the $7 \mathrm{~g}$. feed after seven days, the other after the full 28 . The levels of serum calcium were normal in all, approximately $10 \mathrm{mg}$. \% (Fig. 6E). The inorganic phosphorus levels, on the other hand, were highest, but just under the normal for the rat, in the seven-day groups and in the succeeding groups were progressively lower, reaching their lowest at the end of 28 days. The longer the period of underfeeding, the worse the rachitic state became, as judged by the phosphorus levels in the serum. When we began the semi-starvation experiments, we speculated that, if the underfeeding was continued long enough, the animals would be forced to burn increased amounts of tissue protein and the serum phosphorus level would progressively rise. But the contrary result is in accord with studies of starvation in human beings which show that the maximal destruction of body protein occurred initially and in a week or 10 days dropped to a lower level, as physiological adjustment developed (Benedict, 1915; Howard, Bigham, Eisenberg, Wagner and Bailey, 1946). Again, the values for the inorganic phosphorus tended to be higher, the lower the food allowance, referable to the greater sparing effects on body protein of the larger allowances. 
So our attempts to prevent rickets by partial starvation with the Steenbock-Black diet failed entirely in both aims. Not even the smallest allowances prevented growth or caused even a partial healing.

Attempts to Cure Rickets by Partial Starvation. In a set of sibling experiments we tried to cure rickets by partial starvation. What we hoped to obtain by suddenly reducing the rickets diet, given before freely, to starvation levels was the healing stratum of calcification in the cartilage at the top of the rachitic intermediate zone (the positive 'line test') as in the total starvation experiments. We produced rickets in freshly weaned rats by giving the Steenbock diet freely for 22 days. Then in one group we abruptly reduced the ration to $2 \mathrm{~g}$., in the others to 3, 4, 5, 6 and 7 g., respectively, and killed all at the end of seven days. All showed rickets without a trace of healing histologically. Again the calcium levels were normal (Fig. 6F), the phosphorus levels, at the end of the suddenly imposed week of partial starvation, showed an inverse relationship to the food allowance, once more indicating that the partial starvation had thrown the animals back on their own tissues, but even the smallest feeding was inadequate to produce any healing. These experimental attempts to elicit a curative reaction by partial starvation failed in contrast to the success with total starvation.

Significance of the Starvation Experiments. The Steenbock-Black diet is exceedingly high in carbohydrate, $70 \%$ of the calories. The protein, from vegetable sources, amounts to a little more than $20 \%$. The calcium is in great excess, $1 \cdot 2 \%$, and the phosphorus very low, $0 \cdot 28 \%$. The ratio of calcium to phosphorus is a little more than $4: 1$. The diet is poor from the nutritional viewpoint; rats on it do not gain well. In that respect it seemed suited for prevention of rickets through prevention of growth. From the rickets viewpoint it is drastic, as shown by its preferential use for the line test, since with uniformity it renders the cartilage free of calcium. Herein lie the reasons why our partial starvation experiments turned out negatively. The excess calcium of the diet reduced the absorption of food phosphorus so that the quota of the latter in the serum coming in from the gut was kept low and the carbohydrate through its sparing action reduced the catabolism of body protein, so that the endogenous yield to the serum from that source was kept low. The combined action of these two factors prevented the phosphorus of the serum from rising to precipitation levels required by cartilage and bone.

Had we used a less drastic diet, one which caused only borderline rickets, and possessed at the same time better nutritive quality, permitting longer experimental periods, and had we also used older animals growing more slowly, I believe we could have succeeded in preventing rickets by underfeeding. We are about to attempt this.

Obviously the results of our experiments cannot be transferred to children. The rats all grew. It is doubtful if the child has anything like equal hardihood. Then, too, rickets is not natural to the rat. Given adequate calcium and phosphorus in the ration, it does not require vitamin D. Rickets has to be forced on it by gross defects in the dietary calcium and phosphorus. In contrast, rickets is natural to the child in the sense that he develops it, though the food is rich in calcium and phosphorus. In short the two are very different. But the experiments do have an important suggestive value. The effects of the food restrictions were all in the direction of prevention and cure. The greater restrictions forced the rats to use their body protein, as indicated by the rise in serum phosphorus, but the rise was insufficient to cause calcification. The results make it appear that the body tissues must be drawn on heavily; or, put the other way round, that a small sparing element in the diet may be enough to prevent the body from effecting its own cure.

We have not attempted the experimental study of the toxic factor. Such a study would be difficult of interpretation, though bearing more directly on the problem in the child, since its action might include starvation and be additive to its action by increasing further tissue protein breakdown and at the same time might work the other way round, supplying the factors which are provocative of rickets. We return now to Follis's and my studies on children.

\section{Studies in Children}

Proof that Illness can Precipitate Rickets. The provisional zone of the cartilage is the one closest to the shaft. Calcification there is always the most recent. If rickets had begun on Friday and death had occurred on Sunday, the defects in calcification of the cartilage would be limited to the provisional zone. Some time ago our attention was attracted to defective calcification of the provisional zone in our children showing otherwise exceptional heavily calcified lattices and for long we were puzzled (Fig. 7B). The overcalcified lattice of cartilage matrix extending up to the provisional zone proved that not a trace of rickets had been present in the earlier periods. Clearly, rickets had suddenly set in shortly before the end of life. Realizing that we had evidence that severe illness had precipitated rickets, we wondered whether it had operated by producing some local changes in the cartilage which 
rendered it unable to calcify or had done so by creating some general disturbance in the calcium and phosphorus of the blood, as in ordinary rickets. Accordingly we appealed to Dr. Harold Harrison of the Harriet Lane Home to measure for us serum calcium and phosphorus levels during severe illness and again after recovery and found that he had already done this. Harrison's measurements showed plainly that in severe infections characteristic rachitic depressions of the calcium or phosphorus or both occur as indicated by their reduced values and rebound after recovery. Additional data, showing the same, were kindly furnished by Dr. Mitchell Rubin of Buffalo University Medical School. When we reviewed our cases of lattice formation in the light of Harrison's and Rubin's reports, we found evidence of terminal failure in calcification of the provisional zone in a considerable proportion. Illness can then precipitate rickets and does so in the ordinary way by affecting the calcium and phosphorus concentrations in the blood.

HARRISON'S MEASUREMENTS OF THE EFFECTS OF CA, $P$ AND ALKALINE PHOSPHATASE IN SERUM*

\begin{tabular}{|c|c|c|c|c|c|c|}
\hline \multirow{2}{*}{ Diagnosis } & \multicolumn{3}{|c|}{$\begin{array}{c}\text { Acute Stage } \\
\text { Serum }\end{array}$} & \multicolumn{3}{|c|}{$\begin{array}{c}\text { Convalescence } \\
\text { Serum }\end{array}$} \\
\hline & $\mathrm{Ca}$ & $\mathbf{P}$ & $\begin{array}{l}\text { Phospha- } \\
\text { tase }\end{array}$ & $\mathrm{Ca}$ & $\mathbf{P}$ & $\begin{array}{c}\text { Phospha- } \\
\text { tase }\end{array}$ \\
\hline $\begin{array}{ll}\text { Peritonitis } & \ldots \\
\text { Empyema } & \text {. } \\
\text { Pneumonia } & \text {. } \\
\text { Meningitis } & \text {. } \\
\text { Meningitis } & \text {. } \\
\text { Infantile eczema } \\
\text { Cellulitis }\end{array}$ & $\begin{array}{r}\overline{7 \cdot 3} \\
8 \cdot 3 \\
9 \cdot 3 \\
11 \cdot 4 \\
9 \cdot 7 \\
8 \cdot 5\end{array}$ & $\begin{array}{l}2 \cdot 7 \\
1 \cdot 8 \\
3 \cdot 3 \\
3 \cdot 6 \\
2 \cdot 8 \\
2 \cdot 5 \\
2 \cdot 8\end{array}$ & $\begin{array}{r}\overline{5 \cdot 4} \\
12 \cdot 7 \\
\overline{4 \cdot 9} \\
14 \cdot 9 \\
5 \cdot 9\end{array}$ & $\begin{array}{l}9 \cdot 6 \\
9 \cdot 4 \\
11 \cdot 5 \\
- \\
10 \cdot 0\end{array}$ & $\begin{array}{l}3 \cdot 7 \\
6 \cdot 9 \\
6 \cdot 3 \\
5 \cdot 3 \\
6 \cdot 3 \\
-\end{array}$ & $\begin{array}{l}12 \cdot 3 \\
14 \cdot 2 \\
10 \cdot 4 \\
= \\
\overline{7 \cdot 2} \\
-\end{array}$ \\
\hline
\end{tabular}

* All measurements are in mg. per $100 \mathrm{ml}$.

It may now be anticipated that I go on to show that illness had caused moderate and severe rickets or had intensified its development. But this we were unable to do, for although the 'palaeontological' evidence might reveal that the rickets had suddenly begun or undergone an exacerbation, we could not date the event accurately enough to be sure it could not have preceded the illness. Indeed when it almost certainly fell within the illness, we could not prove that the development was not a natural one with which the illness had naught to do. We did obtain information from a study of trends, but of that later. I now turn to the opposite possibility: Did our studies show that illness could act like vitamin $\mathrm{D}$ on total starvation in the rat and cause a curative response in the form of the Müller stratum, commonly spoken of in x-ray parlance, as 'the line test'?

Can Illness Exert a Curative Effect? In 1858 Müller pointed out that in severe chronic rickets healing showed itself by the formation of a stratum or sheet of calcium salt deposit in the cartilage on the epiphyseal side of the rachitic intermediate zone, actually in what would have been the provisional zone of calcification if the rickets had never existed. The appearance of this line in the X-ray film is usually the first definite indication that healing is occurring. According to experience years ago, when severe rickets was common, 3 teaspoonfuls daily of cod liver oil $(1,200 \mathrm{U}$.) produced the Müller shadow in the $x$-ray film quite regularly by the twenty-first day (Fig. 7C and D). In our series the earliest appearance was 13 days after the administration of 13,000 U. daily.

The reason that calcium salts fall selectively in this zone, in chronic rickets often far removed from the end of the shaft (Fig. 7E), is that it is the one where the cartilage cells contain the glycogen which appears to be implicated in the calcification process. Follis (1950) has demonstrated the presence of glycogen in this zone in rickets and its absence in the older cartilage below, i.e. that between it and the shaft. Apparently the rachitic cartilage loses its glycogen promptly if the calcium and phosphorus concentrations in the body fluids are insufficient to claim it, and the only reason we know why all the cartilage in the rachitic intermediate zone does not calcify at the same time as the provisional zone is that it has become passé, its glycogen being exhausted.

Did infections or severe states of malnutrition or the two in combination cause this line to develop in moderate or severe rickets ?* Beginning with the second month and ending with the beginning of the twenty-third, there were 21 instances of a Müller stratum. In 15 of these its occurrence was explicable on the ground of vitamin D administration; either vitamin $\mathrm{D}$ had been given in the Harriet Lane wards or prescribed in the out-patient department or the mother asserted that it had been given. In an additional instance the stratum was accounted for by the administration of $3 \mathrm{~g}$. of sodium phosphate daily over the last 17 days. Of the five remaining, in three, ages 11,13 and 15 months, deaths had occurred in October, September and August, respectively, so that the presence of the stratum could have been accounted for by exposure to the summer sun. The nutrition in these three children was reported as 'fair' in one and 'good' in the other two. In the remaining two there was no explana-

* The sign is applicable only to cases of moderate or severe rickets in which growth has continued long enough so that the stratum of calcification will stand up on the cartilage to be clear of the shaft. It is not applicable in cases of rickets of very short duration in which it would be merged with the end of the bone and appear merely as an intensification of the calcification of the end. 

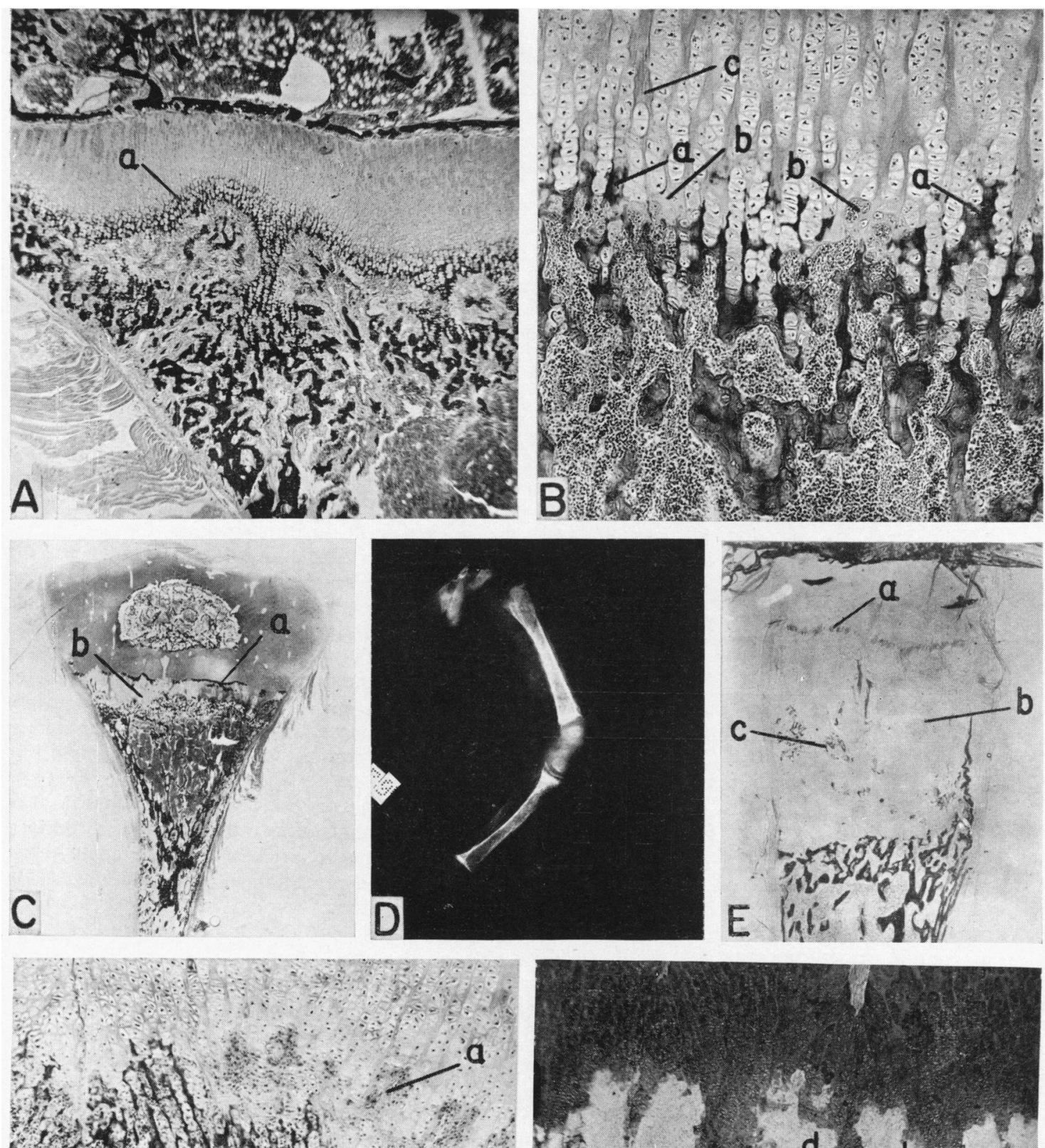

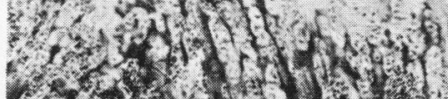

$6 x^{2}+x^{3}+1$

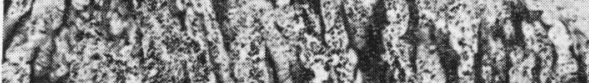

3.

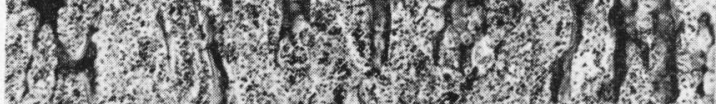

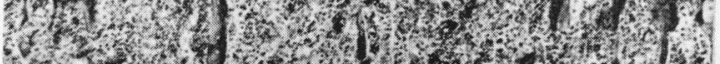

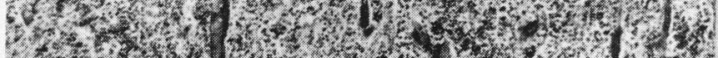

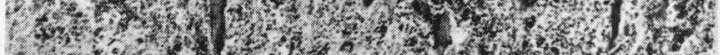

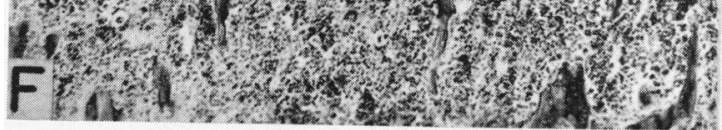

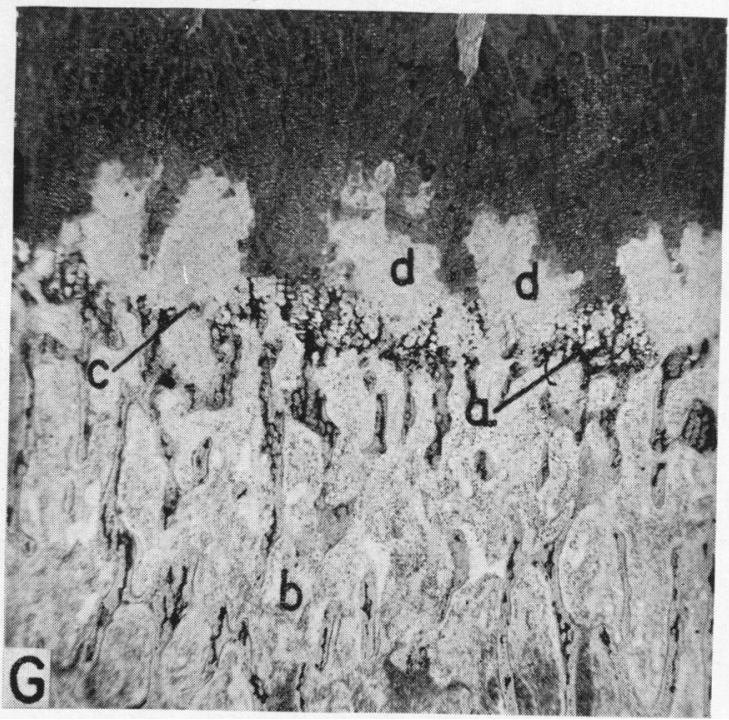

Fig. 7. 
tion found other perhaps than the final illness (suipestifer septicaemia of 14 days' duration in one and protracted dysentery in the other). The nutrition was recorded in one as 'poor' and in the other 'actual emaciation'. Accordingly, in only two of the 21 instances can a healing effect be attributed to severe illness and in them the evidence is not certain.* The possible occurrence of a positive healing effect from illness and malnutrition in these two children is offset by our failure to find any evidence of similar healing in a considerable number of the subjects of severe rickets suffering from most severe protracted illness and severe malnutrition. Any antirachitic effect exerted by them must be small as compared to vitamin D.

\footnotetext{
* In the one death occurred in September, but it seems improbable that this $2 \frac{1}{2}$-months-old infant was exposed to the Baltimore sun Moreover there was no information concerning vitamin $\mathrm{D}$ administration. In the other instance death was in February but four transfusions were given at scattered intervals and it is possible that haemolysis with liberation of phosphate may have occurred.
}

Fig. 7A.-(From H. Harrison) 266; $\times 15$. Undecalcified $\mathrm{Ag} \mathrm{No}$ haematoxylin and eosin. (a) Fresh Müller stratum of Ca-salt deposit in 7-week-old rachitic cat produced by total starvation for 24 hours; serum Ca. $8 \cdot 7$, serum $P 5 \cdot 5 \mathrm{mg}$. \%.

Fig. 7B.-502; $\times 60$. Rib of 11-months-old child dying of generalized tuberculosis. (a) Lattice exhibiting (b) defective calcification of provisional zone, an observation first drawing our attention to the fact that illness can precipitate rickets; (c) pattern of matrix frame of cartilage which determines pattern of shaft, beautifully demonstrated.

Fig. 7c.-J.J.; $\times 3$. Microscopic section, upper tibia from a child with severe rickets, treated with $1,200 \mathrm{U}$. vit. D (C.L.O.) for 21 days when death occurred. (a) Müller line of Ca-salt deposit; (b) rachitic metaphysis, appearing translucent in x-ray film (Fig. 7D) so that the Müller line there stands in relief.

Fig. 7D.-X-ray film of Fig. 7c after death.

FIG. 7E.-Rib from an unknown case of almost unbelievably severe rickets which evidently, from the appearance of the end of the shaft, must have begun suddenly and been total. (a) Müller stratum of Ca-salt deposit, far separated from end of shaft by (b), an enormously deep metaphysis in which lie (c) scattered deposits of Ca-salts.

Fig. 7F. - 1363; $\times$ 40. Rib from malnourished 3-months-old child, dying of widespread tuberculosis. The histological preparation indicates the development of acute severe rickets, Ca-salt deposition having suddenly stopped completely. This is shown by (a) vascularosteoblast complexes wnich have grown to huge, bush-like structures and protrude deep into rachitic cartilage. Undoubtedly the rickets began during the illness, but one cannot say that it might not have developed anyway. The illness showed no blocking effect, if it did not precipitate or intensify the development.

FIG. 7G.-897; $\times 17$. Rib of 2-months-old child, dying of diarrhoea with dehydration of three weeks' duration; viosterol $6,660 \mathrm{U}$. daily for last 23 days. The histological preparation demonstrates the 'trend' of the rickets. Up to (a) the last stratum of Ca-salt deposit, the architecture of, (b) the shaft, looks normal; at (c) gaps in Ca-salt deposition denote beginning of rickets. From (a) on (upwards in the section) the rickets became total. The pale areas (d) represent huge vascular-osteoblast complexes, enveloped in osteoid, derived from the matrix substance of the cartilage; the dark areas separating them are composed of rachitic cartilage by-passed in the irregular invasion process (compare Fig. 5F). The 'trend' in this case was progressive development. Evidently, however, the rickets must have started before the relatively short terminal illness. No evidence of any vitamin D effect.
Does Illness Prevent Rickets by Stopping or Slowing Growth? As has been already pointed out, no growth, no rickets. Do our studies of children indicate that illness can prevent the disease in that way? Follis's analysis showed that of 147 children never having received vitamin $\mathrm{D}, 73$ either had negligible rickets or none (Follis, Park and Jackson, 1952). Of these 73, 23 showed a marked inhibition of growth, if not complete cessation. In the other 50 , growth had not stopped, as shown by histological examination. Our studies revealed, therefore, a group of growing children not requiring vitamin D. Obviously there is no way of knowing, if the 23, not growing, had resumed growth, whether they would or would not have developed rickets, i.e. if failure to grow was actually blocking the disease.

But thwarting rickets by ceasing to grow has only academic interest. If the child lives, growth will out. The question raises the larger one, then, of the relation of rickets to growth. Rickets must depend on a more or less fixed ratio of the rates of calcium and phosphorus supply available to the skeleton over the rate of skeletal growth. If the denominator, bone growth, is diminished, the requirement for calcium and phosphorus is diminished also. Theoretically, then, a small absorption of calcium and phosphorus, caused by a vitamin $\mathrm{D}$ deficiency, may be adequate, if the growth of the skeleton is correspondingly curtailed.

As a matter of fact proof that slow growth can prevent rickets is to be found in the individual subject of rickets. The rates of growth in the long bones vary as follows: Costochondral junction ++++++ , lower femur +++++ , upper femur, upper humerus and both ends of the tibia ++++ , lower radius and ulna, the ulna being slightly the better, +++ , the lower humerus ++ and the upper radius and ulna + , the ulna being the poorer. The histologist may find +++ rickets in the rib and none or only very slight evidence in the upper ulna. The rachitic state is general but the cartilage-shaft junction of the upper ulna fails to manifest it because the greatly restricted growth allows little new cartilage to form and that which does form lingers so long in contact with the tissue fluid that adsorption can exert its effect. In other words the rachitic state does not show there. The trabeculae underneath, however, will exhibit the same osteoid borders as those in the rib.

It does not follow from this that rickets is more prevalent in well nourished than in poorly nourished infants, for in the latter the factor of illness is more frequent, which may impair the calcium-phosphorus metabolism out of proportion to its interference 
with growth. Rickets is more conspicuous in the well nourished child because the gross deformities are larger, but in our experience the severest examples of the disease actually have occurred in malnourished children. In the group never having received vitamin $\mathrm{D}$, Follis's analysis failed to reveal a greater incidence of rickets in the well than in the poorly nourished (Follis et al., 1952).

Trends. We tried to find if under the influence of illness the rickets was increasing or was being turned in the opposite direction toward healing. In the cases in which the natural movement of the disease could be traced in the bone, it was almost wholly in the direction of exacerbation (Fig. 7F).

Is Vitamin D Action Impaired? We hoped to be able to determine if the effectiveness of vitamin D was reduced in severe illness. However, the cases of our study offered too many variables and intangibles for analysis. We did find numerous examples in which during severe infections large amounts of vitamin D for more than five weeks failed to act. But here, as McCance (1947) has emphasized, different individuals vary so greatly in their requirement that conclusions were impossible. The cases of failure were, however, egregious and numerous enough to make impairment seem likely.

\section{Summary}

The earlier part of the lecture was devoted to the study of the growth pattern in uncomplicated rickets and its modification by illness. Under its influence the hyperactive cells lining the trabeculae withered and disappeared, and their growth activity ceased, an effect exactly like that seen in the non-rachitic bone. While the osteoblast could thrive in the low concentrations of calcium and phosphorus of the body fluids, the cartilage cell was incapacitated, being rendered unable to complete its normal maturation cycle necessary for the ingrowth of the shaft and its conversion into bone. In the light of this, the development of the endochondral lesion was traced and in general principle explained. The remainder of the lecture dealt with the effects of illness on rickets itself, i.e. on the abnormal calciumphosphorus equilibrium in the tissue fluids which actually determines it. In order to explore this, the effects of the important factor in illness, inanition, complete and partial, were studied experimentally in the rachitic rat and the mechanism by which inanition exercises its antirachitic action was clarified. While complete inanition caused a deposition of calcium salts in the rachitic cartilage, partial starvation failed to produce any healing effect or to prevent the development of the disease or to stop growth wholly. In the child proof was offered that severe illness could precipitate rickets and that it did this by depressing the calcium and phosphorus concentrations in the blood, exactly as in vitamin $\mathrm{D}$ deficiency. The balance of evidence from several different sides favoured the view that the common influence of illness is to aggravate rickets already established. The relation of rickets to growth was considered and the conclusion reached that retardation of growth per se could exert a preventive influence. With the exception of two possible instances, the study of 21 rachitic children showing the Müller sign failed to disclose that illness, including malnutrition, could cause a healing action like vitamin $D$. It seemed probable that illness may affect rickets in two distinct ways, one favouring, the other opposing, and that generally speaking, the former is the more powerful and tends to predominate.

\section{REFERENCES}

Benedict, F. G. (1915). A Study of Prolonged Fasting. Publication No. 203, Carnegie Institute of Washington.

Follis, R. H. (1950). Metabolic Interrelations. Trans. 2nd Conf. January 9, 1950, Josiah Macy Jr. Foundation, New York.

Park, E. A. and Jackson, D. (1952). Bull. Johns Hopk. Hosp., 91, 480.

Harrison, H. E. and Harrison, H. C. (1941). Amer. J. Physiol., 134, 781.

Howard, J. E., Bigham, R. S., Eisenberg, H., Wagner, D. and Bailey, E. (1946). Bull. Johns Hopk. Hosp., 78, 282

McCance, R. A. (1947). Quart. J. Med., 16, 33 .

McCollum, E. V., Simmonds, N., Shipley, P. G. and Park, E. A (1922). Johns Hopk. Hosp. Bull, , 33, 31.

Müller, H. (1858) Z. wiss. Zool., 9, 147.

Schmorl, G. (1909). Ergebn. inn. Med. Kinderheilk., 4, 402. 